\title{
Our Understanding of Well-differentiated Thyroid Cancer
}

\author{
${ }^{1}$ Christopher Thompson, ${ }^{2}$ lain J Nixon
}

\begin{abstract}
Through significant contributions to our understanding of risk factors, prognostic indicators and management of welldifferentiated thyroid cancer (WDTC), Prof Jatin Shah has contributed much to the field of thyroid cancer in recent times. Many of the guidelines used in WDTC management today are a testament to his less-aggressive, dedicated and individualised approach. This article seeks to both review the current understanding of WDTC and to outline these contributions in a special issue dedicated to the career of Prof Shah.
\end{abstract}

Keywords: Lymph nodes, Risk stratification, Thyroidectomy, Well-differentiated thyroid cancer.

How to cite this article: Thompson C, Nixon IJ. Our Understanding of Well-differentiated Thyroid Cancer. Int J Head Neck Surg 2017;8(2):64-70.

Source of support: Nil

Conflict of interest: None

\section{INTRODUCTION}

Well-differentiated thyroid cancer (WDTC) is increasingly common in the United States and worldwide. ${ }^{1-7}$ Therefore, it is critical that clinicians who deal with this disease understand the biology of the condition and the approach to case assessment and subsequent treatment. This issue is dedicated to the career of Prof Jatin Shah, and there are few clinicians who could claim to have contributed more to the field of thyroid cancer than him. Although much recent focus has been on papillary thyroid cancer (PTC), the term WDTC includes PTC, follicular thyroid cancer, and Hurthle cell cancers, and this grouping remains relevant as described in the American Joint Committee on Cancer staging manual. ${ }^{8}$ This article aims to review the current state of understanding of WDTC. We examine factors that are pertinent to initial case assessment, consider how these integrate in to risk stratification, and how this then influences ultimate management of patients with WDTC.

\footnotetext{
${ }^{1}$ Trainee,${ }^{2}$ Consultant and Senior Lecturer

${ }^{1}$ Department of Otolaryngology, Head and Neck Surgery, NHS Lothian, Edinburgh, UK

${ }^{2}$ Department of ENT, NHS Lothian UK; Department of Otolaryngology, Head and Neck Surgery, NHS Lothian Edinburgh, UK

Corresponding Author: lain J Nixon, Consultant and Senior Lecturer, Department of ENT, NHS Lothian UK; Department of Otolaryngology, Head and Neck Surgery, NHS Lothian Edinburgh, UK, e-mail: lain.nixon@nhs.net
}

\section{Patient Age}

Well-differentiated thyroid cancer is unlike other human malignancies in that patient age at presentation has a significant impact on outcome. It is currently not entirely clear why age imparts such a significant effect, but it is without doubt that survival in young patients exceeds that in older patients. As such, all staging systems consider age as a critical factor, ${ }^{9-11}$ and although some systems incorporate age as a continuous variable,${ }^{10}$ most use a cut-off and 45 years has become the standard internationally (Table 1).

As the incidence of WDTC increases, there has been a surge in the number of older patients diagnosed. ${ }^{12}$ These patients are classically considered to be at higher risk than the younger cohort. Age 45 has long been used largely because the median age of most thyroid databases is around 45 years. Therefore, this presents a statistically convenient cut-point. However, there is increasing evidence that age 45 years may be too low and that a higher cut-point would not only improve the statistical performance of the staging system but also prevent around 10\% of patients from being overstaged. ${ }^{13,14}$

Following initial clinical suspicion that the age cut-off was too low, Prof Shah led the largest multi-institutional study to date examining this issue and validated the finding that a change in age cut-off from 45 to 55 years would result in an improved staging system for WDTC. ${ }^{15}$

These findings along with other group's results have provided evidence to the international staging committees, which is thought likely to result in a shift in international staging of WDTC. ${ }^{16}$ Not only will this improve the performance of these predictive models, but it is hoped that downstaging of a significant number of patients

Table 1: American joint committee on cancer (AJCC) staging system for well-differentiated thyroid carcinoma based on age

\begin{tabular}{cl}
\hline \multicolumn{2}{c}{ Well-differentiated thyroid cancer } \\
\hline Age $<45$ years & Any T, Any N, M0 \\
Stage 1 & Any T, Any N, M1 \\
Stage 2 & \\
Age $\geq 45$ years & $\mathrm{T} 1, \mathrm{~N} 0, \mathrm{M} 0$ \\
Stage 1 & $\mathrm{~T} 2, \mathrm{~N} 0, \mathrm{M} 0$ \\
Stage 2 & $\mathrm{~T} 3$ or T1/2 N1a \\
Stage 3 & $\mathrm{~T} 4 \mathrm{a}$ or T1/2/3 N1b \\
Stage 4a & $\mathrm{T} 4 \mathrm{~b}, \mathrm{Any} \mathrm{N}, \mathrm{M0}$ \\
Stage 4b & $\mathrm{M} 1$ \\
Stage 4c &
\end{tabular}


will lead to a reduction in treatment intensification with resultant reduction in unnecessary morbidity from treatment of patients previously inappropriately considered at high risk of disease-specific death.

\section{Primary Thyroid Tumors}

The majority of WDTC presents with identifiable disease within the thyroid gland. Although clinical history (particularly hoarseness and dysphagia) and examination (both of the neck and the larynx) are critical at the point of initial assessment, almost all patients will go on to have ultrasound (US) assessment. ${ }^{17,18}$ In addition to US, fine needle aspiration biopsy of suspicious nodules is now considered the standard approach to assessment of the primary tumor. Having made a diagnosis of WDTC, a variety of factors must be considered in relation to the primary tumor itself.

Tumor size has long been associated with outcome. 9,10,19,20 The outcome for patients with large tumors is less favorable in comparison to those with small tumors. In common with age, tumor size has long been described around a series of cut-off points (Table 2).

Although current systems describe a difference in staging between smaller and larger tumors confined to the thyroid gland [i.e., no extrathyroid extension (ETE)], there are little data to support a change in outcome for this generally indolent disease.

There has long been pressure to consider small volume tumors, particularly microcarcinomas $(<1 \mathrm{~cm})$ as

Table 2: AJCC TNM staging system for WDTC

\begin{tabular}{|c|c|}
\hline \multicolumn{2}{|r|}{ Definition } \\
\hline T0 & No evidence of primary tumor \\
\hline $\mathrm{T} 1 \mathrm{a}$ & Tumor $<1 \mathrm{~cm}$, no ETE \\
\hline $\mathrm{T} 1 \mathrm{~b}$ & Tumor $>1 \mathrm{~cm}$ but $<2 \mathrm{~cm}$ in greatest dimension, no ETE \\
\hline $\mathrm{T} 2$ & Tumor $>2 \mathrm{~cm}$ but $<4 \mathrm{~cm}$ in greatest dimension, no ETE \\
\hline T3 & $\begin{array}{l}\text { Tumor }>4 \mathrm{~cm} \text { in greatest dimension limited to the thyroid } \\
\text { or any size tumor with minimal ETE (e.g., extension } \\
\text { into strap muscles or surrounding soft tissues) }\end{array}$ \\
\hline $\mathrm{T} 4 \mathrm{a}$ & $\begin{array}{l}\text { Tumor of any size extending beyond the thyroid } \\
\text { capsule to invade surrounding soft tissues, e.g., larynx, } \\
\text { trachea, esophagus, or recurrent laryngeal nerve }\end{array}$ \\
\hline $\mathrm{T} 4 \mathrm{~b}$ & $\begin{array}{l}\text { Tumor of any size invading prevertebral fascia, carotid } \\
\text { artery or mediastinal vessels }\end{array}$ \\
\hline No & No metastatic nodes \\
\hline $\mathrm{N} 1 \mathrm{a}$ & $\begin{array}{l}\text { Metastases to level VI (pretracheal, paratracheal, and } \\
\text { prelaryngeal lymph nodes) }\end{array}$ \\
\hline \multirow[t]{2}{*}{$\mathrm{N} 1 \mathrm{~b}$} & $\begin{array}{l}\text { Metastases to unilateral, bilateral, or contralateral } \\
\text { cervical lymph nodes (levels I, II III, IV, or V) }\end{array}$ \\
\hline & $\begin{array}{l}\text { or retropharyngeal or superior mediastinal lymph nodes } \\
\text { (level VII) }\end{array}$ \\
\hline M0 & No distant metastases \\
\hline M1 & Distant metastases \\
\hline
\end{tabular}

ETE: Extrathyroid extension; TNM: Tumor nodes metastases their own risk category (pT1); this has been resisted by a number of authors including Prof Shah. There is little impact on outcome until disease reaches a significant size (currently considered $4 \mathrm{~cm}$ ) at which tumor size becomes an independent predictor of survival. ${ }^{21}$

Again, by resisting the temptation to reduce the size cut-off for the lowest risk tumors, an increased number of patients remain in the low-risk categories. This is entirely appropriate as there is no clinically significant difference in survival between those with 1 and $2 \mathrm{~cm}$ intrathyroid tumors, a fact consistently proven by the work of Prof Shah. ${ }^{21-23}$

A second factor that should be considered in assessment of the primary tumor in patients with WDTC is whether there is evidence of ETE. For those patients with gross ETE, particularly ETE which invades posteriorly into the recurrent laryngeal nerve, airway, or esophagus, the impact on outcome is significant. ${ }^{24}$ In contrast, when the operating surgeon identifies no gross ETE but on histological analysis microscopic ETE is confirmed, this has little if any bearing on overall prognosis. ${ }^{22}$ However, current staging systems fail to record a difference between these two situations. Again, work led by Prof Shah has demonstrated the difference in outcome for these two situations, work, i.e., likely to influence the refinement of staging systems in future. ${ }^{22}$

\section{Regional Lymph Nodes}

Few issues are as controversial as regional lymph nodes in the field of WDTC. Although nodal metastases are rare in both follicular and Hurthle cell carcinomas, this is not the case for patients with PTC.

It was initially thought that nodal metastases conferred no impact on survival in PTC. Indeed, some groups actually considered nodal metastases as protective. ${ }^{25}$ However, this finding was disproven, as groups including that of Prof Shah showed that nodal disease in young patients had little impact on survival, whereas in older patients the effect was more significant. ${ }^{26}$

It is now well accepted that nodal metastases do impact on outcome, in terms of both survival for older patients and recurrence for all. ${ }^{17}$ As such in patients with nodal disease identified on pre-treatment investigation, therapeutic surgery is recommended.

However, PTC metastasizes early and often. This finding is demonstrated in the work of groups who consider prophylactic surgery mandatory for all cases of PTC irrespective of clinical nodal status (i.e., cN0/cN1). ${ }^{27}$ Rates of nodal involvement exceed $40 \%$ in many studies even in cN0 cases, reinforcing the need for prophylactic nodal surgery in the minds of both clinicians who adopt 
this approach and their patient group who are informed of the result.

These results would seem to support the approach of prophylactic nodal surgery in all patients. In 2009, the American Thyroid Association published guidelines for the management of WDTC, which stated that prophylactic surgery should be considered in PTC. ${ }^{28}$ This was interpreted by many as official support for prophylactic neck dissection.

However, not all authors agreed. Although large volume nodal disease is accepted to be associated with increased risk, particularly in older patients, small volume occult nodal metastases pose less of a risk. ${ }^{29,30}$ In the central neck, they are challenging to identify preoperatively due to the limitations of US. This further strengthens the argument for prophylactic surgery. However, it is now apparent that although nodal metastases are often present in the clinically uninvolved neck, it is very rare that they progress from small volume nodes to clinically relevant disease. ${ }^{31}$

The surgical approach to PTC in Memorial Sloan Kettering Cancer Center(MSKCC) had long rejected the notion that prophylactic nodal surgery resulted in clinical benefit. ${ }^{32,33}$ In the cN0 neck, although involved nodes could be demonstrated by neck dissection, such an approach, which results in increased rates of complication, was shown not to be associated with benefit. Rates of recurrence and disease-related death in patients who did not undergo neck dissection were shown to be extremely low to the point that justification of prophylactic surgery could not be made. ${ }^{34}$

As such, international guidelines now do not support prophylactic lateral neck dissection and highlight the fact that prophylactic central neck dissection may not be required in the majority of cases of PTC. This evolution in the approach to management based upon an improved understanding of disease biology again serves to protect low-risk patients from overtreatment and subsequent iatrogenic injury with little or no oncological benefit.

\section{Risk Stratification}

An understanding of the factors that predict survival in patients with WDTC led to the development of risk stratification systems. ${ }^{10,20,35,36}$ Such systems are based on recognized independently significant risk factors including patient age, tumor size, presence of extrathyroid extension, and presence of distant metastases.

Many risk stratification systems have been proposed, based upon the work of different international institutions. In truth, all are very similar and none have gained universal acceptance. The concept of risk stratification allows clinicians to consider the patient and tumor features of each case and integrate these details into an overall risk estimate that can be used in patient counseling and treatment planning.

Prof Shah developed the MSKCC "GAMES" risk stratification system (Table 3). By considering young patients as low risk and older patients as high risk, and then considering small intrathyroid tumors as low risk and large, invasive, or metastatic tumors as high risk, cases could be stratified accordingly. Low-risk patients with low-risk tumors have excellent oncological outcomes. High-risk patients with high-risk tumors have poor oncological outcomes. High-risk patients with low-risk tumors and low-risk patients with high-risk tumors represent an intermediate group.

It is less important which system clinicians adopt than that they do adopt a risk-adapted approach to the management of WDTC. It is only by understanding the biology of the disease that rational patient counseling and therapeutic decision-making can be achieved.

\section{Approach to Therapy}

When faced with a patient diagnosed with WDTC, the clinician must consider a wide range of factors that have an influence on treatment recommendations. An understanding of indications for radioactive iodine (RAI) therapy is critical in planning, as is an appreciation of the

Table 3: MSKCC cause specific mortality risk classification system (GAMES)

\begin{tabular}{|c|c|c|c|c|c|}
\hline Risk level & $\begin{array}{l}\text { American thyroid } \\
\text { association staging } \\
\text { system (TNM) }\end{array}$ & Description & $\begin{array}{l}\text { Evidence suggests } \\
\text { disease specific } \\
\text { survival improvement }\end{array}$ & $\begin{array}{l}\text { Evidence suggests } \\
\text { disease free survival } \\
\text { improvement }\end{array}$ & $\begin{array}{l}\text { Radioactive } \\
\text { iodine Indicated? }\end{array}$ \\
\hline \multirow[t]{2}{*}{ Low } & T1a, N0, M0 & Tumor $<1 \mathrm{~cm}$ & No & No & No \\
\hline & T1b/T2, N0, M0 & Tumor $1-4 \mathrm{~cm}$ & No & Conflicting & Not routine \\
\hline \multirow{4}{*}{$\begin{array}{l}\text { Low to } \\
\text { intermediate }\end{array}$} & T3, N0, M0 & Tumor $>4 \mathrm{~cm}$ & Conflicting & Conflicting & Consider \\
\hline & T3, N0, M0 & Microscopic ETE (any size) & No & Conflicting & Consider \\
\hline & T1-3, N1a, M0 & $\begin{array}{l}\text { Central neck compartment } \\
\text { lymph nodes }\end{array}$ & $\begin{array}{l}\text { No (consider if } \\
>45 \text { years) }\end{array}$ & Conflicting & Consider \\
\hline & $\mathrm{T} 1-3, \mathrm{~N} 1 \mathrm{~b}, \mathrm{M} 0$ & $\begin{array}{l}\text { Lateral neck or mediastinal } \\
\text { lymph nodes }\end{array}$ & $\begin{array}{l}\text { No (consider If } \\
>45 \text { years) }\end{array}$ & Conflicting & Consider \\
\hline \multirow[t]{2}{*}{ High } & $\mathrm{T} 4$, any $\mathrm{N}$ or $\mathrm{M}$ & Gross ETE (any size) & Yes & Yes & Yes \\
\hline & $\mathrm{M} 1$, any $\mathrm{T}$ or $\mathrm{N}$ & Distant metastases & Yes & Yes & Yes \\
\hline
\end{tabular}


real-life risk of complications from the proposed treatment options.

Radioactive iodine has a currently decreasing role in the management of WDTC. ${ }^{37-40}$ In high-risk patients, those with distant metastase and those with highvolume nodal disease, RAI will be routinely recommended following primary surgery. Therefore, total thyroidectomy is the preferred primary procedure.

Previously, RAI would also be considered for lower risk patient groups, including all patients with $>1 \mathrm{~cm}$ tumors. This approach dates back to findings from early 20 th century practice, ${ }^{41}$ reinforced by more recent findings that have ultimately been shown to be flawed. It is now accepted, based upon the work of Prof Shah and others, that RAI has limited benefit in all but the highest risk cases (Table 4). As such, an increasing number of patients are now potentially candidates for less-aggressive primary surgery. ${ }^{23,42-45}$

When considering the optimal approach to therapy in WDTC, one must understand not only the risk posed to the patient by the disease but also the risk of treatment itself. Although eminent international thyroid surgeons have extremely low rates of recurrent laryngeal nerve injury and hypocalcemia associated with thyroidectomy and central neck dissection, this is unlikely to be true for the average surgeon. ${ }^{46}$ Recurrent nerve injury has a significant impact on quality of life for patients, and permanent hypocalcemia requiring calcium replacement therapy is extremely inconvenient and disruptive for those who suffer it. When considering the potential oncological benefit conferred by more aggressive surgery on a case-by-case basis, the clinician must also consider the degree of increased iatrogenic risk that the patient will be exposed to as a result. ${ }^{47}$

In terms of the surgical approach to regional nodes, a compartment-orientated neck dissection is recommended for all patients with metastatic disease. ${ }^{48}$ If this involves the central neck, bilateral levels VI and VII should be dissected. If the lateral neck is also involved, dissection of levels IIa, III, IV, and V is recommended in a "comprehensive neck dissection."

Table 4: American thyroid association recommendations on postoperative RAI

\begin{tabular}{lll}
\hline Risk level & Patient factor & Tumor factor \\
\hline Low risk & Age $<45$ years & $\begin{array}{l}\text { Papillary carcinoma } \\
\text { M0/no ETE/size }<4 \mathrm{~cm}\end{array}$ \\
High risk & Age $>45$ years & $\begin{array}{l}\text { Follicular/Hurthle cell } \\
\text { carcinoma } \\
\text { M1/ETE/size }>4 \mathrm{~cm}\end{array}$ \\
$\begin{array}{l}\text { Low-risk case } \\
\text { Intermediate- } \\
\text { risk case }\end{array}$ & Low-risk patient & Low-risk patient \\
$\begin{array}{l}\text { High-risk } \\
\text { case }\end{array}$ & High-risk patient & High-risk tumor \\
\hline
\end{tabular}

For those patients without evidence of nodal disease, the majority will derive little or no benefit from prophylactic surgery and therefore, a conservative approach will maintain oncological benefit without exposing patients to higher risk of surgical complication. Patients with invasive primary disease (cT3/4) who require extensive primary surgery are at significant risk of nodal disease even when considered $\mathrm{cN} 0$ on investigation. These patients represent the only group who should routinely be considered for prophylactic central neck dissection in the absence of preoperative suspicion of nodal disease.

In terms of selecting the extent of primary surgery, for high-risk cases (ETE or metastatic disease), total thyroidectomy will facilitate RAI. For low-risk patients, a more critical approach should be taken (Fig. 1). In patients with multinodular disease, most authors would recommend total thyroidectomy due to the high rates of multicentricity reported in PTC. Patients whose thyroid has been exposed to radiation are considered at higher risk of developing disease (even if such tumors are not themselves high risk) and as such again total thyroidectomy is recommended. For all other patients, thyroid lobectomy should be considered.

In clinical practice, a balance of patient, tumor, and treatment factors should be made in tailoring treatment to the individual. No longer should there be a onesize-fits-all approach to WDTC cancer management. For low-risk patients with uninodular small volume disease, particularly those who are professional voice users, lobectomy may be preferred. This minimizes surgical risk with no impact on oncological outcome. However, the contralateral lobe will continue to be monitored during follow-up. For larger volume disease in patients who may not be available for follow-up or in those patients with psychological reservations against any possible under treatment the treatment team may

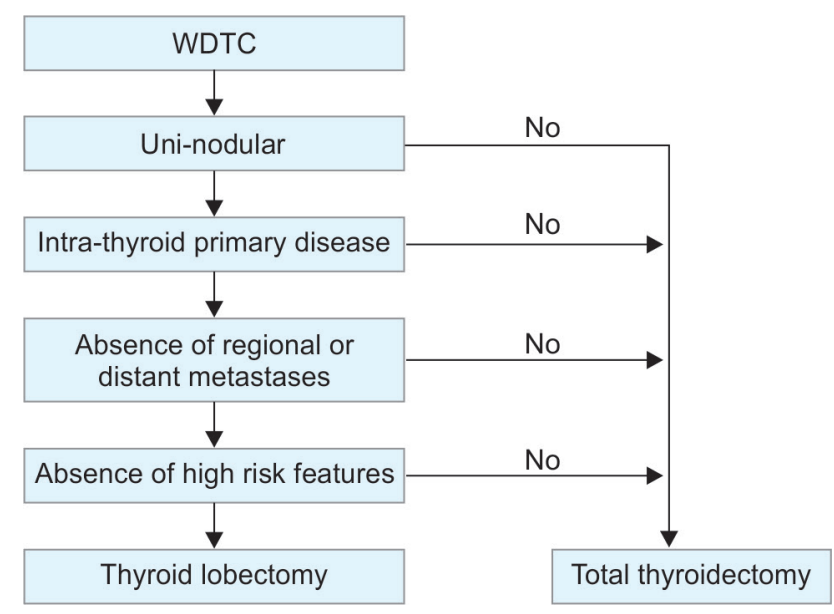

Fig. 1: Algorithm for selection of primary thyroid procedure 


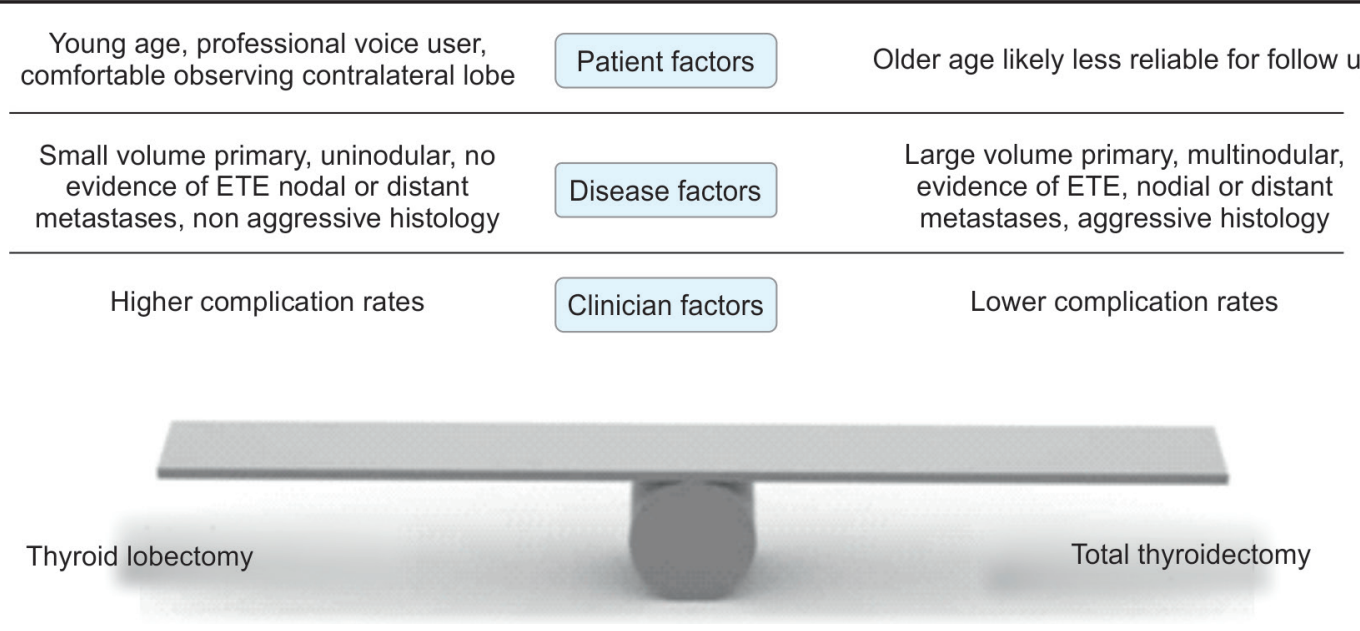

Fig. 2: Factors to consider in surgical decision-making

recommend total thyroidectomy, if this can be achieved with minimal surgical risk (Fig. 2).

\section{CONCLUSION}

Over the past century, great strides have been made in the understanding of thyroid cancer biology and the impact of treatment on outcome. An appreciation of the factors that are associated with outcome in terms of patient age, primary tumor features, and the presence of regional or distant metastatic disease have given rise to accurate risk stratification systems that allow clinicians to individualize therapy for their patients.

Prof Shah's contribution in this field cannot be understated. His recognition, not only of which risk factors were critical to outcome but also how they should be best applied in clinical practice, has led to significant progress in this field. His leadership in research and clinical practice has led to some of the largest and most influential studies in this field.

Perhaps even more remarkable than this contribution is his insight into the impact of therapy on outcome. At a time when all seemed to have abandoned less than total thyroidectomy and few people were happy to consider the central neck for observation in PTC, he continued to lead the MSKCC group championing this less aggressive approach. His dedicated and methodical approach not only to his group's surgical practice but also to their continued determination to disseminate the oncological results of this approach now see international guidelines moving to support his long-standing beliefs.

This is made more remarkable by the observation that throughout this period he is seemingly the one with most to lose. Many clinicians feel they should offer the most aggressive treatment possible in the face of cancer, irrespective of the potential for complication. High-volume surgeons have the lowest complication rates in thyroid surgery, and Prof Shah is the world's most renowned head and neck surgeon. As such, his complication rate is likely to be among the lowest in the world. Therefore, if anyone would seem to be best placed to adopt an aggressive surgical approach it would be him and his team at MSKCC. Instead, this high-volume center continues to place the patient at the center of clinical decision-making and as such they have shaped much of what we consider to be the contemporary approach to WDTC.

As WDTC continues to increase in incidence across the world, an increasing number of patients will require assessment and treatment. By recognizing the factors which should shape the approach to risk assessment and therapy selection, in addition to understanding the potential harm that treatment itself can cause, a balance can be reached to optimize both oncological and functional outcome in the management of the individual who presents with WDTC.

\section{REFERENCES}

1. Davies L, Welch HG. Increasing incidence of thyroid cancer in the United States, 1973-2002. JAMA 2006 May 10;295(18): 2164-2167.

2. Enewold L, Zhu K, Ron E, Marrogi AJ, Stojadinovic A, Peoples GE, Devesa SS. Rising thyroid cancer incidence in the United States by demographic and tumor characteristics, 1980-2005. Cancer Epidemiol Biomarkers Prev 2009 Mar;18(3): 784-791.

3. Chen AY, Jemal A, Ward EM. Increasing incidence of differentiated thyroid cancer in the United States, 1988-2005. Cancer 2009 Aug 15;115(16):3801-3807.

4. Kilfoy BA, Zheng T, Holford TR, Han X, Ward MH, Sjodin A, Zhang Y, Bai Y, Zhu C, Guo GL, et al. International patterns and trends in thyroid cancer incidence, 1973-2002. Cancer Causes Control 2009 Jul;20(5):525-531.

5. Olaleye O, Ekrikpo U, Moorthy R, Lyne O, Wiseberg J, Black M, Mitchell D. Increasing incidence of differentiated thyroid cancer in South East England: 1987-2006. Eur Arch Otorhinolaryngol 2011 Jun;268(6):899-906. 
6. Aschebrook-Kilfoy B, Ward MH, Sabra MM, Devesa SS. Thyroid cancer incidence patterns in the United States by histologic type, 1992-2006. Thyroid 2011 Feb;21(2):125-134.

7. McNally RJ, Blakey K, James PW, Gomez Pozo B, Basta NO, Hale J. Increasing incidence of thyroid cancer in Great Britain, 1976-2005: age-period-cohort analysis. Eur J Epidemiol 2012 Aug;27(8):615-622.

8. Amin MB, Edge SB, Greene FL, Byrd DR, Brookland RK, Washington MK, Gershenwald JE, Compton CC, Hess KR, Sullivan DC, et al. AJCC Staging Manual. Springer; 2017.p. 1024

9. Shah JP, Loree TR, Dharker D, Strong EW, Begg C, Vlamis V. Prognostic factors in differentiated carcinoma of the thyroid gland. Am J Surg 1992 Dec;164(6):658-661.

10. Hay ID, Bergstralh EJ, Goellner JR, Ebersold JR, Grant CS. Predicting outcome in papillary thyroid carcinoma: development of a reliable prognostic scoring system in a cohort of 1779 patients surgically treated at one institution during 1940 through 1989. Surgery 1993 Dec;114(6):1050-1057.

11. Haugen BR, Alexander EK, Bible KC, Doherty GM, Mandel SJ, Nikiforov YE, Pacini F, Randolph GW, Sawka AM, Schlumberger M, et al. 2015 American thyroid association management guidelines for adult patients with thyroid nodules and differentiated thyroid cancer. Thyroid 2016 Jan;26(1):1-133.

12. Hughes DT, Haymart MR, Miller BS, Gauger PG, Doherty GM. The most commonly occurring papillary thyroid cancer in the United States is now a microcarcinoma in a patient older than 45 years. Thyroid 2011 Mar;21(3):231-236.

13. Nixon IJ, Kuk D, Wreesmann V, Morris L, Palmer FL, Ganly I, Patel SG, Singh B, Tuttle RM, Shaha AR, et al. Defining a valid age cutoff in staging of well-differentiated thyroid cancer. Ann Surg Oncol 2016 Feb;23(2):410-415.

14. Hendrickson-Rebizant J, Sigvaldason H, Nason RW, Pathak KA. Identifying the most appropriate age threshold for TNM stage grouping of well-differentiated thyroid cancer. Eur J Surg Oncol 2015 Aug;41(8):1028-1032.

15. Nixon IJ, Wang LY, Migliacci JC, Eskander A, Campbell MJ, Aniss A, Morris L, Vaisman F, Corbo R, Momesso D, et al. An international multi-institutional validation of age 55 years as a cutoff for risk stratification in the AJCC/UICC staging system for well-differentiated thyroid cancer. Thyroid 2016 Mar;26(3):373-380.

16. Adam MA, Thomas S, Hyslop T, Scheri RP, Roman SA, Sosa JA. Exploring the relationship between patient age and cancer-specific survival in papillary thyroid cancer: rethinking current staging systems. J Clin Oncol 2016 Dec 20;34(36):4415-4420.

17. Haugen BR, Alexander EK, Bible KC, Doherty GM, Mandel SJ, Nikiforov YE, Pacini F, Randolph GW, Sawka AM, Schlumberger M, et al. 2015 American thyroid association management guidelines for adult patients with thyroid nodules and differentiated thyroid cancer: The American thyroid association guidelines task force on thyroid nodules and differentiated thyroid Cancer. Thyroid 2016 Jan;26(1):1-133.

18. Perros P, Boelaert K, Colley S, Evans C, Evans RM, Gerrard Ba G, Gilbert J, Harrison B, Johnson SJ, Giles TE, et al. Guidelines for the management of thyroid cancer. Clin Endocrinol (Oxf) 2014 Jul;81 Suppl 1:1-122.

19. Haigh PI, Urbach DR, Rotstein LE. AMES prognostic index and extent of thyroidectomy for well-differentiated thyroid cancer in the United States. Surgery 2004 Sep;136(3):609-616.
20. Shaha AR, Shah JP, Loree TR. Risk group stratification and prognostic factors in papillary carcinoma of thyroid. Ann Surg Oncol 1996 Nov;3(6):534-538.

21. Wang LY, Nixon IJ, Palmer FL, Thomas D, Tuttle RM, Shaha AR, Patel SG, Shah JP, Ganly I. Comparable outcomes for patients with pT1a and pT1b differentiated thyroid cancer: Is there a need for change in the AJCC classification system? Surgery 2014 Dec;156(6):1484-1489.

22. Nixon IJ, Ganly I, Patel S, Palmer FL, Whitcher MM, Tuttle RM, Shaha AR, Shah JP. The impact of microscopic extrathyroid extension on outcome in patients with clinical T1 and T2 well-differentiated thyroid cancer. Surgery 2011 Dec;150(6):1242-1249.

23. Shah JP, Loree TR, Dharker D, Strong EW. Lobectomy versus total thyroidectomy for differentiated carcinoma of the thyroid: a matched-pair analysis. Am J Surg 1993 Oct;166(4):331-335.

24. Wang LY, Nixon IJ, Patel SG, Palmer FL, Tuttle RM, Shaha A, Shah JP, Ganly I. Operative management of locally advanced, differentiated thyroid cancer. Surgery 2016 Sep;160(3):738-746.

25. Cady B, Sedgwick CE, Meissner WA, Wool MS, Salzman FA, Werber J. Risk factor analysis in differentiated thyroid cancer. Cancer 1979 Mar;43(3):810-820.

26. Hughes CJ, Shaha AR, Shah JP, Loree TR. Impact of lymph node metastasis in differentiated carcinoma of the thyroid: a matched-pair analysis. Head Neck 1996 Mar-Apr;18(2):127-132.

27. Hartl DM, Leboulleux S, Al Ghuzlan A, Baudin E, Chami L, Schlumberger M, Travagli JP. Optimization of staging of the neck with prophylactic central and lateral neck dissection for papillary thyroid carcinoma. Ann Surg 2012 Apr;255(4): 777-783.

28. Cooper DS, Doherty GM, Haugen BR, Kloos RT, Lee SL, Mandel SJ, Mazzaferri EL, McIver B, Sherman SI, Tuttle RM, et al. Management guidelines for patients with thyroid nodules and differentiated thyroid cancer. Thyroid 2006 Feb;16(2):109-142.

29. Randolph G, Duh QY, Heller KS, Livolsi VA, Mandel SJ, Steward D, Tufano RP, Tuttle RM; American Thyroid Association Surgical Affairs Committee's Taskforce on Thyroid Cancer Nodal Surgery. The prognostic significance of nodal metastases from papillary thyroid carcinoma can be stratified based on the size and number of metastatic lymph nodes, as well as the presence of extranodal extension ata surgical affairs committee's taskforce on thyroid cancer nodal surgery. Thyroid 2012 Nov;22(1):1144-1152.

30. Urken ML, Haser GC, Likhterov I, Wenig BM. The impact of metastatic lymph nodes on risk stratification in differentiated thyroid cancer: have we reached a higher level of understanding? Thyroid 2016 Apr;26(4):481-488.

31. Nixon IJ, Ganly I, Patel SG, Morris LG, Palmer FL, Thomas D, Tuttle RM, Shah JP, Shaha AR. Observation of clinically negative central compartment lymph nodes in papillary thyroid carcinoma. Surgery 2013 Dec;154(6):1166-1172.

32. Shaha AR. Controversies about the central compartment in thyroid cancer. Editorial regarding the article "Clinical impact of cervical lymph node involvement and central neck dissection in patients with papillary thyroid carcinoma: a retrospective analysis of 368 cases" by Alexandre Bozec et al. Eur Arch Otorhinolaryngol 2011 Aug;268(8):1097-1099.

33. Iyer NG, Shaha AR. Central compartment dissection for well differentiated thyroid cancer ... and the band plays on. Curr Opin Otolaryngol Head Neck Surg 2011 Apr;19(2):106-112. 
34. Nixon IJ, Wang LY, Ganly I, Patel SG, Morris LG, Migliacci JC, Tuttle RM, Shah JP, Shaha AR. Outcomes for patients with papillary thyroid cancer who do not undergo prophylactic central neck dissection. Br J Surg 2016 Feb;103(3):218-225.

35. Cady B, Rossi R. An expanded view of risk-group definition in differentiated thyroid carcinoma. Surgery 1988 Dec;104(6):947-953.

36. Byar DP, Green SB, Dor P, Williams ED, Colon J, van Gilse HA, Mayer M, Sylvester RJ, van Glabbeke M. A prognostic index for thyroid carcinoma. A study of the E.O.R.T.C. Thyroid cancer cooperative group. Eur J Cancer 1979 Aug;15(8):1033-1041.

37. Mallick U, Harmer C, Hackshaw A, Moss L, Io NTMG. Iodine or Not (IoN) for low-risk differentiated thyroid cancer: the next UK National Cancer Research Network randomised trial following HiLo. Clin Oncol (R Coll Radiol) 2012 Apr;24(3):159-161.

38. Schlumberger M, Catargi B, Borget I, Deandreis D, Zerdoud S, Bridji B, Bardet S, Leenhardt L, Bastie D, Schvartz C, et al. Strategies of radioiodine ablation in patients with low-risk thyroid cancer. N Engl J Med 2012 May 03;366(18):1663-1673.

39. Nixon IJ, Ganly I, Patel SG, Palmer FL, Di Lorenzo MM, Grewal RK, Larson SM, Tuttle RM, Shaha A, Shah JP. The results of selective use of radioactive iodine on survival and on recurrence in the management of papillary thyroid cancer, based on Memorial Sloan-Kettering Cancer Center risk group stratification. Thyroid 2013 Jun;23(6):683-694.

40. Nixon IJ, Patel SG, Palmer FL, Dilorenzo MM, Tuttle RM, Shaha A, Shah JP, Ganly I. Selective use of radioactive iodine in intermediate-risk papillary thyroid cancer. Arch Otolaryngol Head Neck Surg 2012 Dec 1;138(12):1141-1146.

41. Mazzaferri EL, Young RL, Oertel JE, Kemmerer WT, Page CP. Papillary thyroid carcinoma: the impact of therapy in 576 patients. Medicine (Baltimore) 1977 May;56(3):171-196.
42. Hay ID, Grant CS, Taylor WF, McConahey WM. Ipsilateral lobectomy versus bilateral lobar resection in papillary thyroid carcinoma: a retrospective analysis of surgical outcome using a novel prognostic scoring system. Surgery 1987 Dec;102(6):1088-1095.

43. Mendelsohn AH, Elashoff DA, Abemayor E, St John MA. Surgery for papillary thyroid carcinoma: is lobectomy enough? Arch Otolaryngol Head Neck Surg 2010 Nov;136(11): 1055-1061.

44. Nixon IJ, Ganly I, Patel SG, Palmer FL, Whitcher MM, Tuttle RM, Shaha A, Shah JP. Thyroid lobectomy for treatment of well differentiated intrathyroid malignancy. Surgery 2012 Apr;151(4):571-579.

45. Vaisman F, Momesso D, Bulzico DA, Pessoa CH, da Cruz MD, Dias F, Corbo R, Vaisman M, Tuttle RM. Thyroid lobectomy is associated with excellent clinical outcomes in properly selected differentiated thyroid cancer patients with primary tumors greater than $1 \mathrm{~cm}$. J Thyroid Res 2013;2013:398194.

46. Chadwick D, Kinsman R, Walton P. The British Association of Endocrine \& Thyroid Surgeons Fourth National Audit Report: Dendrite Clinical Systems Ltd, The Hub, Station Road, Henley-on-Thames, Oxfordshire RG9 1AY: United Kingdom; 2012.

47. Nixon IJ, Shah JP. Well differentiated thyroid cancer: Are we over treating our patients? Eur J Surg Oncol 2014 Feb;40(2): 129-132.

48. Stack BC, Jr., Ferris RL, Goldenberg D, Haymart M, Shaha A, Sheth S, Sosa JA, Tufano RP; American Thyroid Association Surgical Affairs Committee. American Thyroid Association consensus review and statement regarding the anatomy, terminology, and rationale for lateral neck dissection in differentiated thyroid cancer. Thyroid 2012 May;22(5): 501-508. 